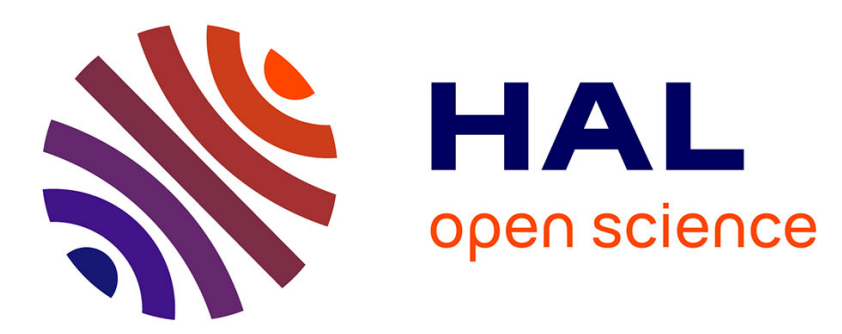

\title{
Heart rate sensors acceptability: data reliability vs. ease of use
}

\author{
Mathieu Simonnet, Bernard Gourvennec
}

\section{To cite this version:}

Mathieu Simonnet, Bernard Gourvennec. Heart rate sensors acceptability: data reliability vs. ease of use. 13th Annual International Body Sensor Networks Conference (BSN 2016), Jun 2016, San Francisco, CA, United States. pp.94 - 98, 10.1109/BSN.2016.7516239 . hal-01359076

\section{HAL Id: hal-01359076 https://hal.science/hal-01359076}

Submitted on 2 Sep 2016

HAL is a multi-disciplinary open access archive for the deposit and dissemination of scientific research documents, whether they are published or not. The documents may come from teaching and research institutions in France or abroad, or from public or private research centers.
L'archive ouverte pluridisciplinaire HAL, est destinée au dépôt et à la diffusion de documents scientifiques de niveau recherche, publiés ou non, émanant des établissements d'enseignement et de recherche français ou étrangers, des laboratoires publics ou privés. 


\title{
Heart rate sensors acceptability: data reliability $v s$. ease of use
}

\author{
M.Simonnet (Télécom Bretagne / dpt LUSSI, UMR CNRS 6285 / Lab-STICC, France) and \\ B.Gourvennec (Télécom Bretagne / dpt LUSSI, LOUSTIC Lab, France)
}

\begin{abstract}
In the present study we focused on heart rate sensors and compared the acceptability and usability of the various devices candidates to feed the PRECIOUS (PREventive Care Infrastructure based On Ubiquitous Sensing) system. More precisely, smart-watch, chest-belt and 2-points-electrodes have been tested by users during 24 hours. Each device test lead to consult lifestyle reports about stress, sleep and physical activity. During this experimentation 11 participants completed different acceptability questionnaires. The first results interpretation revealed which sensor is the most acceptable and gave insight into how data reliability of the different devices influenced their respective acceptability in the daily life.
\end{abstract}

\section{INTRODUCTION}

Nowadays, lifestyle monitoring are becoming mature enough to propose innovative answer to chronic diseases such as type II diabetes (T2D) and cardio vascular diseases (CVD). Assistive technologies allow to conduct clinical trials outside the lab and to perform experimentation of everyday physiological monitoring in the wild.

The "PREventive Care Infrastructure based On Ubiquitous Sensing" (PRECIOUS) European project ${ }^{2}$ aims to improve motivation for a healthy life by providing the end-users with a lifestyle dashboard. The system collects information about the user from a variety of devices that measure food intake, physical activity, stress levels and sleep patterns. Links between these key lifestyle aspects are important in delivering an overall picture of the users' health status.

To track activities and sleep, accelerometer technologies such as pedometers are widely deployed. However they quickly reach their own limits when people need to record heart rate (HR) during another physical activity than walking or running. For example, such classical exercises as biking, swimming or even pulling-up in a fitness center do not trigger any input with a pedometer. Conversely, wearing a HR sensor along the day is supposed to ensure the monitoring of physical efforts during a day (e.g. environmental stresses and recovery periods). However, until now, HR sensors were only used by athletes during scheduled trainings, or by healthcare providers during dedicated cares.

This addresses the issue of the HR sensors usability and acceptability during long time in the daily life.

\section{HEART RATE DEVICES AND ACCEPTABILITY}

\section{A. Heart rate medical individual devices}

There are three main types of digital medical records [1]:

- Electronic Medical Record (EMR), which are healthcare providers centered

- $\quad$ Electronic Health Record (EHR), used when patient health information is to be shared across different health providers;

- $\quad$ Personal Health Record (PHR), whose set up, access and management is carried out by the patient.

The last one fits with the PRECIOUS project ambition to allow users to collect and analyze their own HR data by themselves.

HR data is fundamental to produce a relevant interpretation about sleep, stress and physical activity [2]. More precisely, heart rate variability (HRV) gives an insight about the the sympathetic (activation) and parasympathetic (recovery) activities of the autonomic nervous system.

There are three main types of connected devices on the market at the moment:

- Devices collecting electrocardiogram (ECG) level information via electrodes

- Devices collecting ECG level information via chest belt

- Devices collecting photoplethysmogram (PPG) level information via watch

Devices collecting ECG via electrodes (e.g. FirstBeat Bodyguard 2, Biopack, Holter, ...) are very accurate [3] and capable of collecting very long measurements regarding both the amount and accuracy of the data and the battery life. The drawback is that they are not waterproof and require the use of electrodes. It could make them hardly convenient for an everyday use.

Devices collecting ECG via chestbelt (e.g. Suunto, Garmin or POLAR chestbelt,...) are mainly used to give information about and during exercise as it could be not very fun to wear a belt for extended periods, and especially during sleep. The data quality is typically good (except during night when the belt can sometimes slip from the right position). The belt can be worn when swimming too.

Devices collecting PPG are optical sensors (e.g. PulseOn, fitbit, smarwatches, ...). They measure HR by illuminating the blood vessels on a person's wrist with a LED in order to track blood flow. The measurement accuracy declines when a

\footnotetext{
${ }^{1}$ http://www.thepreciousproject.eu
} 
person is in motion, and it is not very precise, generally speaking, because blood flow does not provide a distinct "peak" similar to an electrical signal originating from the heart [4]. Optical sensors is thus less accurate than ECG-level devices. However, precision could be acceptable [3]. In addition, the battery life can be a real problem. The optical devices however could be the most comfortable for the user.

In order evaluate the respective reliability of those three types of device, we compared their data with the data from a three points electrodes considered as medical reference (i.e. Biopac MP150) [5]. In this short preliminary study, three participants spent three minutes with the four HR devices simultaneously (i.e. three-points-electrodes, two-pointselectrodes, chestbelt and smartwatch). During a short sequence of three minutes participants performed light exercise and recovered. We gathered heart rate from each devices every seconds. Results revealed that the two-points-electrodes data presented a strong positive correlation with the three-pointselectrodes $(r=0.9836027, \mathrm{p}<.01)$. We also found a positive correlation between the chestbelt data and the three-pointselectrodes $(r=0.9680904, p<.01)$. Finally, data coming from the smartwatch were also significantly positively correlated $(\mathrm{r}=0.9548085, \mathrm{p}<.01)$ (Figure 1)

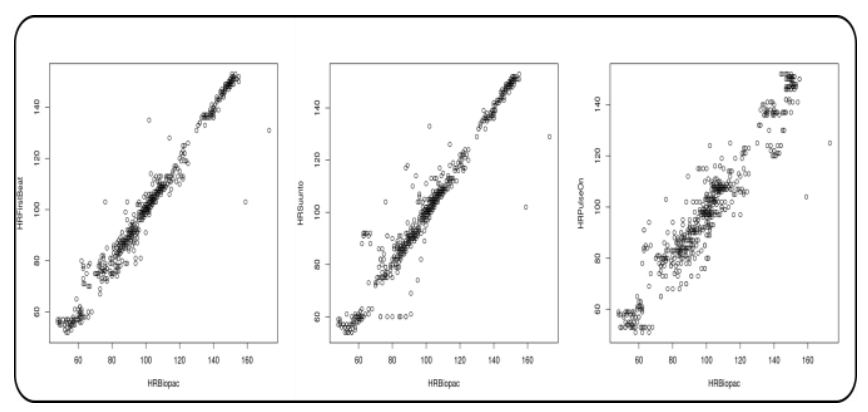

Figure 1: Correlations between the data from the two-points-electrodes (Firstbeat), the chest belt (suunto), the smartwatch (pulseOn) and the threepoints-electrodes (Biopack) considered as the medical reference.

Taking into account this differences between various sensors, the PRECIOUS system setup needs to assess which HR sensor is the most "appropriate" depending on T2D and CVD end-users features such as age, gender, morphological details, favorite activity and daily constraints.

\section{B. Technology and acceptability}

An appropriate device is a device that the user would accept to wear. Thus, our first concern is to assess the acceptability of the different types of devices. Technology Acceptance Model (TAM) has been used extensively in research that looks at the acceptance of new technology [6]. The main idea of this model is that a device is acceptable depending on the relation between the "perceived usefulness" and the "perceived ease of use".

$$
\text { Acceptability }=\frac{\text { perceived usefulness }}{\text { perceived ease of use }}
$$

A recent study from the American Association of Retired Persons (AARP) proposed to ninety two old people to test seven activity and sleep trackers in their daily life to assess usability. Results revealed that "to be valued as useful, activity and sleep trackers must first be effective and easy to use" [7]. This finding is straightly consistent with the TAM basics and reinforces our idea to assess HR monitoring devices using the relationship between data reliability perception and inherent daily constraints.

\section{Research questions:}

Can we expect that users would accept to wear a HR sensor regularly during $24 \mathrm{~h}$ ? Which kind of HR sensor is the best candidate to provide the user with the minimum of constraints but with a good data reliability at the same time?

\section{C. METHOD}

\section{A. Participants}

As the PRECIOUS system aims at preventing T2D and CVD, we perform the following study with both clinical and general population samples. We plan to recruit at least 32 participants to test different HR sensors. Until now, 14 participants have taken part in this experiment and the results of 11 of those have been analyzed. This population is composed of 8 males and 3 females. Among them 5 persons are healthy and 6 suffer from a CVD. One person is also obese (Body Mass Index $(\mathrm{BMI})>30)$.

\section{B. Equipment}

As described below, the respective acceptability of the 3 following types of HR sensors (Figure 2) were compared.

- The Firstbeat bodyguard 2 (2 points electrods)

- The Suunto smart sensor (chestbelt)

- $\quad$ The PulseOn watch (PPG)

Each sensor presents different characteristics (table I).

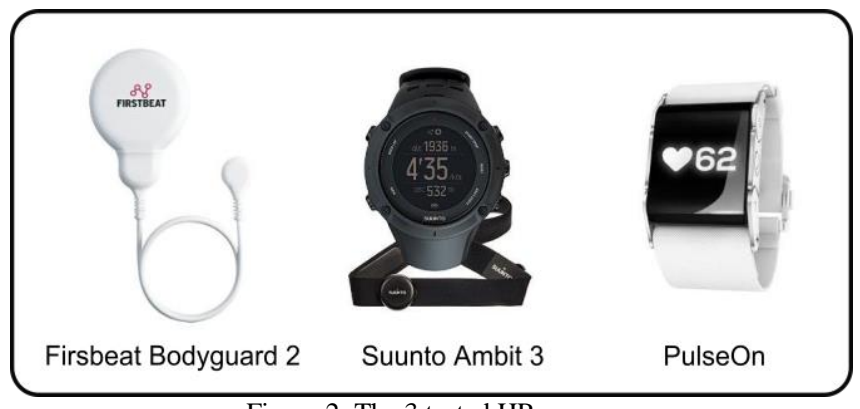

Figure 2: The 3 tested HR sensors

TABLE I. HR DEVICES FEATURES

\begin{tabular}{|l|l|l|l|}
\hline & Firstbeat & Suunto & Pulse On \\
\hline Battery life & 6 days & 6 days & 10 hours \\
\hline "Showerproof" & No & Yes & Yes \\
\hline "SwimProof" & No & Yes & No \\
\hline 24h-maintenance & electrodes & None & recharging \\
\hline HR display & No & Yes & Yes \\
\hline
\end{tabular}

\section{Situation}

Each participant first received instructions on how to use the device. Then s/he wore the sensor during 24 hours and filled an agenda with the physical activity, work and sleep times. At the end of the 24 hours period, the HR report (Figure 3) was generated and consulted by the participant with a specialist. Based on HRV analysis from the Firstbeat analytics algorithm, the report provide users with stress and recovery times. Proportions and quality are given about the whole 24 
hours. "Physical activity analysis" is more detailed with light exercise and reinforcement activity description, peak training effect and kilocalories burned. Specifically, "work analysis" gave the stress and recovery proportion whereas "sleep analysis" also showed the quality of recovery, still based on HRV. Each participant tested the $3 \mathrm{HR}$ devices in a counterbalanced order.

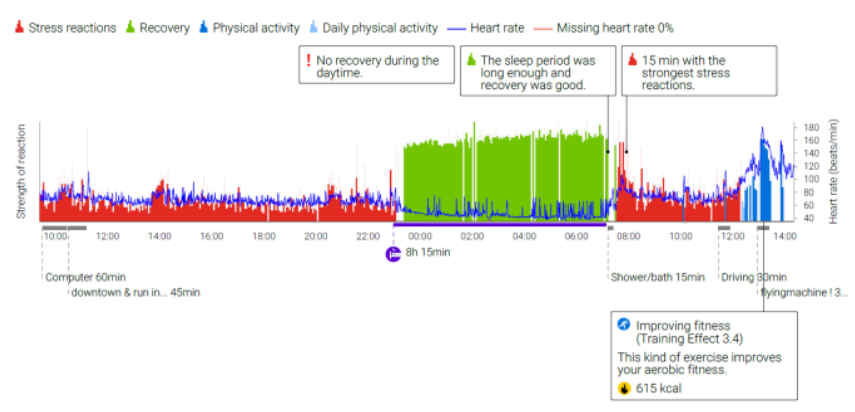

Figure 3: 24-hours Firstbeat report example for the participant 2.

\section{Data Collection}

After each device 24 hours test, participants filled a usability questionnaire. More precisely they completed the 10 questions from the System Usability Scale (SUS) [8], adapted for HR sensors. This well-known questionnaire allowed to obtain a usability score but also an acceptability score. To do so, we calculated the ratio between the scores from the questions about "constraints to use" (i.e. perceived ease of use) and about "data reliability" (i.e. perceived usefulness).

At the end, participants filled a comparison's questionnaire to try to identify which device is more appropriate for which activity. Since anonym personal information are also gathered, links between people characteristics and devices preferences could also be retrieved.

\section{RESUlts}

\section{A. System Usability Scale scores}

First results on this 11 people sample already showed that the SUS score of the smartwatch $($ mean=57) is under the average (68) whereas the SUS scores of the electrodes (78) and the chestbelt (83) are over. A pairwise Wilcoxon statistic test revealed significant differences between the smartwatch and the electrodes $(\mathrm{V}(9)=51, \mathrm{p}<.05)$ on the one hand and between the smartwatch and the chestbelt $(\mathrm{V}(9)=51, \mathrm{p}<.05)$ on the other hand (Figure 4).

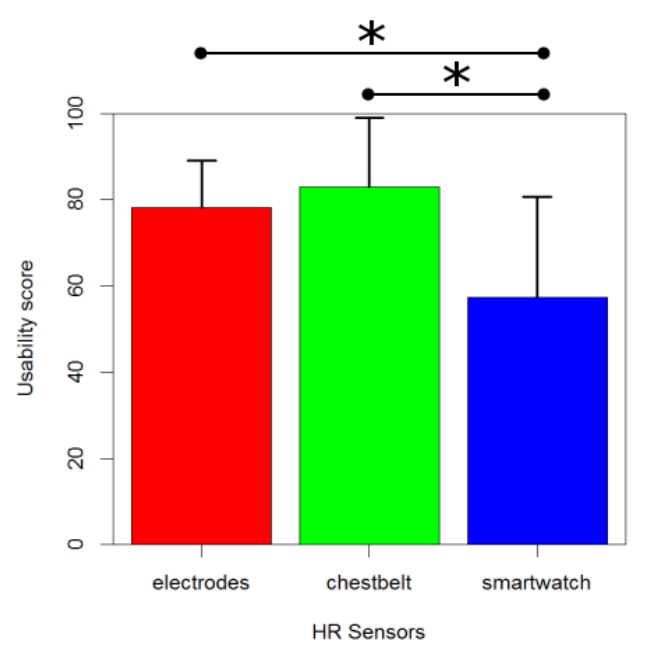

Figure 4: System scale usability scores for each HR sensors.

According to the acceptability concept quoted above, the analysis of the relationship between perceived reliability and perceived ease of use could explain this first result.

\section{B. Perceived ease of use scores}

Participants answered the question "I find that there is too many constraints to use this sensors" (i.e. to assess the perceived ease of use) with a score of 2.8/5 for the electrodes, a score of $2 / 5$ for the chestbelt and a score of 2.6/5 for the smartwatch. These differences are not significant (Figure 5).

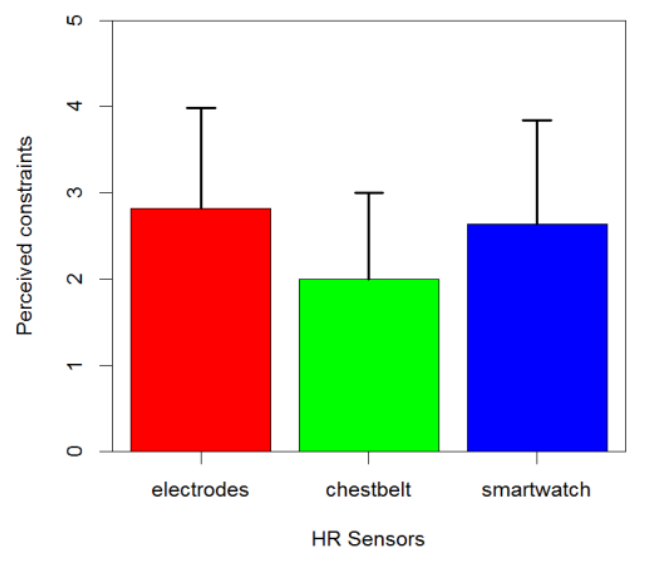

Figure 5: Perceived constraints for each HR sensor

\section{Perceived usefulness scores}

Participants answered to the question "are you confident with this sensor" (i.e. to assess the perceived reliability/usefulness) with a score of $4.3 / 5$ for the electrodes, a score of $4.3 / 5$ for the chestbelt and a score of $2.8 / 5$ for the smartwatch. From a statistical point of view, there is a significant difference between the perceived data reliability of electrodes and smartwatch $(\mathrm{V}(9)=2.5, \mathrm{p}<.05)$ and between chestbelt and smartwatch $(\mathrm{V}(9)=3, \mathrm{p}<.05)$ (Figure 6). 


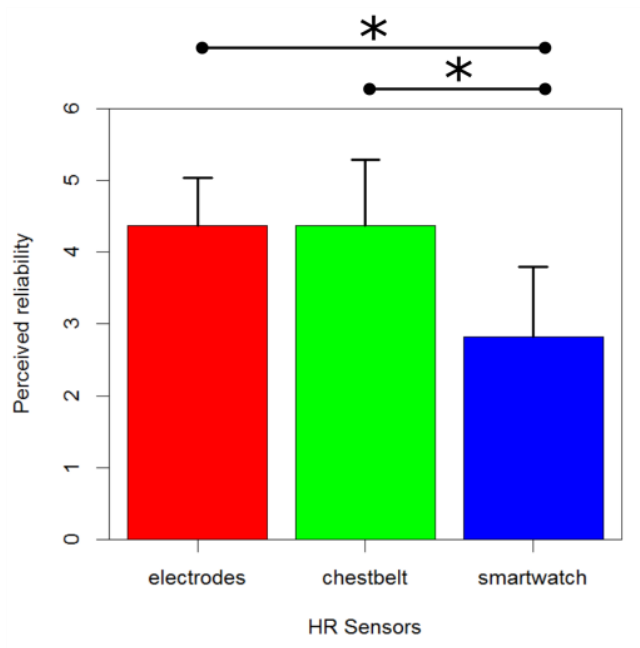

Figure 6: Perceived data reliability for each HR sensor.

Thus participants perceived the HR data coming from the PPG devices less reliable than the data recorded by the two ECG devices (chestbelt and electrodes).

\section{Technology acceptance model-like score}

When applying the acceptability relationship (i.e. reliability / constraints) we found a score of 1.9 for the electrodes, a score of 2.8 for the chestbelt and a score of 1.4 for the smartwatch. The only significant difference is between the chestbelt and the smartwatch $(\mathrm{V}(9)=53, \mathrm{p}<.05)$ (Figure 7). This result is consistent with the usability one and seems to confirm that the reliability of the data play a major role in the HR sensors acceptability.

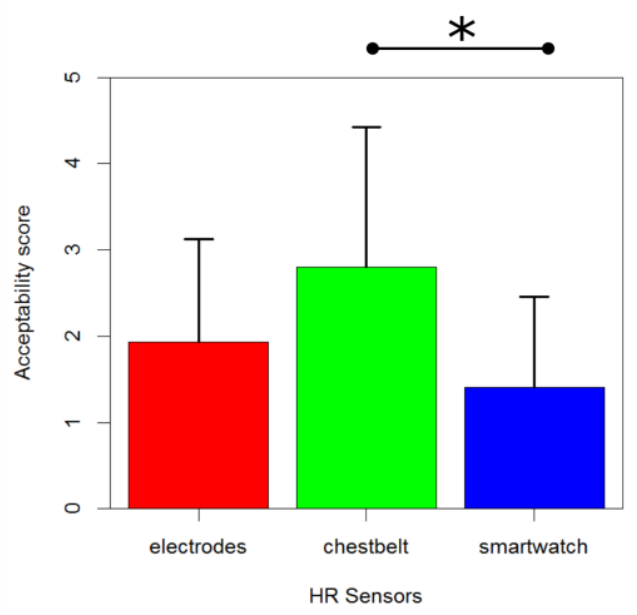

Figure 7: Acceptability score for each HR sensor

Finally, we analyzed the interactions between SUS score from the HR sensors and health conditions of the participants. Electrodes obtained 81.5 with suffering participants versus 79.5 with healthy ones. Chest belt obtained 80.5 from suffering persons versus 84.5 from the healthy population. Smartwatch obtained 59.5 from people with cardiovascular problems versus 52 from people without any apparent problem. None significant difference appeared. Thus, to date with this sample, we did not detect any influence of the health condition on the devices preferences.

\section{DISCUSSION}

\section{A. The most acceptable device}

The first question in this "working-progress" research is to identify which HR sensors is the most acceptable in the daily life among electrodes, chestbelt and smartwatch. The first findings from the first 11 people taking part in our experiment suggested that the chestbelt is the most appropriate device. Indeed, the "Suunto smart sensor" 24hours daily life experience lead to a SUS score of 83 against 78 for the "Firstbeat bodyguard" electrodes and 57 for the "Pulse On" smartwatch.

This result is consistent with the TAM-like score. Indeed, the relationship between perceived ease of use (i.e. constraints) and perceived usefulness (i.e. data reliability) revealed a higher chestbelt score. The reason of this preference seems to come from the perceived reliability of the data more than the constraints caused by the device. Actually no difference is found in the perceived ease of use whereas the perceived usefulness of the smartwatch is lower than the electrodes and chestbelt ones. It could therefore be assumed that the chestbelt is the best compromise to monitor HR in the daily life.

\section{B. The activity influence}

To date, we have not observed that people from different category would prefer to use different devices but it could be a future finding. However when asking these 11 first participants which device they would like to use for the different daily life activities, answers were different for the physical activity and for the sleeping period. By this respect, 7 participants of 11 claimed that they would use the chestbelt for the physical activities versus $2 / 11$ for the electrodes and $2 / 11$ for the smartwatch. This tendency is not found for the sleeping period during which 5 participants of 11 would choose the electrodes, 5/11 would choose the chestbelt and $1 / 11$ would prefer the smartwatch.

Interviews with participants allowed to go further in depth and revealed different underlying reasons for these differences. Firstly, several users appreciated to see the HR displays during physical activity whereas it was not relevant during sleeping period. They also mentioned the waterproof necessity to record HR during the aquatic activities (e.g. swimming). Thus the only device providing user with HR display and able to function during aquatic activities at the same time is the chestbelt. About sleeping period, participants reported that the requirement to keep the smartwatch bracelet tightened could lead to uncomfortable feeling during the night.

\section{Current limits and future work}

It is important to bear in mind the possible bias in these responses since this experiment is still in progress. Thus, we will complete the tested sample up to 32 participants in the following weeks. However, some methodology studies about usability concluded that experiments with $5( \pm 1)$ or $10( \pm 2)$ 
participants generally reveal up to $80 \%$ of the usability issues [9], [10]. As a consequence, the current results should deserve to be taken into account by researchers who wish investigate these daily HR sensors usability and acceptability issues.

\section{ACKNOWLEDGMENT}

Thanks to the participants who have taken the time to try to improve understanding on how to improve lifestyle with assistive heart rate technology.

We also thank the LOUSTIC (Lab to Observe Usage of Technology for information and Communication) and the Firstbeat Company which gave us the means to realize this experiment.

Eventually, we thank the European Commission for funding this project.

\section{REFERENCES}

[1] A. Santos, J. Macedo, A. Costa, and M. J. Nicolau, "Internet of Things and Smart Objects for M-health Monitoring and Control," Procedia Technol., vol. 16, pp. 1351-1360, 2014.

[2] T. Myllymäki, H. Rusko, H. Syväoja, T. Juuti, M.-L. Kinnunen, and H. Kyröläinen, "Effects of exercise intensity and duration on nocturnal heart rate variability and sleep quality," Eur. J. Appl. Physiol., vol. 112, no. 3, pp. 801-809, 2012.

[3] J. Parak and I. Korhonen, "Accuracy of Firstbeat Bodyguard 2 beat-to-beat heart rate monitor," master degree report, 2014.

[4] D.-G. Jang, S. Park, M. Hahn, and S.-H. Park, "A Real-Time Pulse Peak Detection Algorithm for the Photoplethysmogram," Int. J. Electron. Electr. Eng., vol. 2, no. 1, pp. 45-49, 2014.

[5] E. Gil, L. Sornmo, and P. Laguna, "Detection of heart rate turbulence in photoplethysmographic signals," 2011 Comput. Cardiol., pp. 665-668, 2011.

[6] F. D. Davis, "Perceived usefullness, perceived ease of use and user acceptance of information technology," MIS Quaterly, vol. 13, no. 3, pp. 319-340, 1989.

[7] AARP, "Building a better tracker: Older consumers weigh in on activity and sleep monitoring devices,", report, 2015.

[8] J. Brooke, "SUS: A 'quick and dirty' usability scale," in Usability evaluation in industry, P. W. Jordan, B. Thomas, B. A. Weerdmeester, and I. L. McClelland, Eds. London, UK: Taylor \& Francis, 1996, pp. 189-194.

[9] J. Nielsen, "How Many Test Users in a Usability Study?," 2011. [Online]. Available: http://www.nngroup.com/articles/how-manytest-users/.

[10] W. Hwang and G. Salvendy, "Number of People Required for Usability Evaluation: The $10 \pm 2$ Rule.," Commun. ACM, vol. 53, no. 5, pp. 130-133, 2010. 